\title{
CAPACIDADE ANTIOXIDANTE DE HORTALIÇAS USUALMENTE CONSUMIDAS ${ }^{1}$
}

\author{
Enayde de Almeida MELO ${ }^{2, *}$, Maria Inês Sucupira MACIEL ${ }^{2}$, Vera Lúcia Arroxelas Galvão LIMA², \\ Fernanda Lídia Lemos LEAL ${ }^{3}$, Ana Carla da Silva CAETANO ${ }^{4}$, Rosilda Josefa NASCIMENTO³.
}

\begin{abstract}
RESUMO
Como objetivo de avaliar a capacidade antioxidante de 15 hortaliças comercializadas na Cidade do Recife, extratos metanólicos foram testados quanto a atividade antioxidante em sistema modelo $\beta$-caroteno/ácido linoléico e a habilidade de seqüestrar o radical estável 1,1-difenil-2-picrilhidrazil (DPPH). Todas as hortaliças investigadas exibiram propriedade antioxidante, entretanto a ação foi diferenciada entre os vegetais. Os extratos metanólicos da couve folha, tomate, batata, couve-flor, repolho verde, espinafre e alface crespa, com percentual de inibição superior a $70 \%$, foram os mais eficazes em seqüestrar o radical livre. Os extratos metanólicos da alface lisa, cebola branca e vagem apresentaram ação moderada (60-70\% de inibição), enquanto que a cebola roxa, chuchu, pepino e cenoura exibiram a mais fraca capacidade de seqüestrar o radical DPPH. No sistema modelo $\beta$-caroteno/ácido linoléico, os extratos metanólicos do espinafre e couve-folha exibiram a mais elevada atividade antioxidante (superior a $70 \%$ ). Ação antioxidante moderada (60-70\%) foi exibida pelos extratos da alface lisa, cebola branca e couve-flor, enquanto que os do chuchu, cenoura, pepino, tomate e vagem, com atividade inferior a $60 \%$, foram considerados com fraca ação antioxidante. As hortaliças testadas podem ser vistas como fontes dietéticas de antioxidantes que podem trazer benefícios à saúde, portanto o seu consumo deve ser estimulado.

Palavras-chave: hortaliças, ação antioxidante; DPPH; sistema modelo $\beta$-caroteno/ácido linoléico.
\end{abstract}

\section{SUMMARY}

ANTIOXIDANT CAPACITY OF VEGETABLES COMMONLY CONSUMED. This study was carried out to determine the antioxidant capacity of 15 vegetables commonly consumed in Recife - PE, Brazil. Methanol extracts were screened for their antioxidant activity using two tests: DPPH free radical scavenging and $\beta$-carotene/linoléico acid assay. All vegetables showed antioxidant properties however the action was differentiated among the kinds of vegetables. The methanol extracts of collard greens, tomatoes, potatoes, cauliflowers, green cabbage, spinach and lettuce "crespa" had the highest percentage in terms of free radical scavenging activities (> 70\%). A moderate activity $(60-70 \%)$ was shown by lettuce "lisa", white onion and green beans while purple onion, chayote, cucumber and carrot had the lowest free radical scavenging activities. In the $\beta$-carotene/linoleic acid assay, spinach and collard greens extracts showed strong antioxidant activity (> 70\%). The lettuce "lisa", white onion and cauliflower had a moderate action (60-70\%) while the chayote, carrot, cucumber, tomato and green bean showed weak antioxidant activity. The results indicate that vegetables which were evaluated may provide a source of dietary antioxidant therefore their consumption must be encouraged.

Keywords: vegetables, antioxidant action; DPPH; $\beta$-carotene/linoleic acid model system.

\section{1 - INTRODUÇÃO}

No organismo humano, a atividade metabólica normal produz constantemente radicais livres. Estas moléculas, geradas in vivo, reagem com DNA, RNA, proteínas e outras substâncias oxidáveis, promovendo danos que podem contribuir para o envelhecimento e a instalação de doenças degenerativas, como câncer, aterosclerose, artrite reumática, entre outras. A autoxidação dos ácidos graxos insaturados, componente da membrana celular, é apontada por RAMARATHNAM et al. [23] como o processo oxidativo que ocorre mais freqüentemente no organismo humano.

Evidências epidemiológicas têm demonstrado que existe uma forte correlação inversa entre o consumo regular de frutas e hortaliças e a prevalência de algumas doenças de-

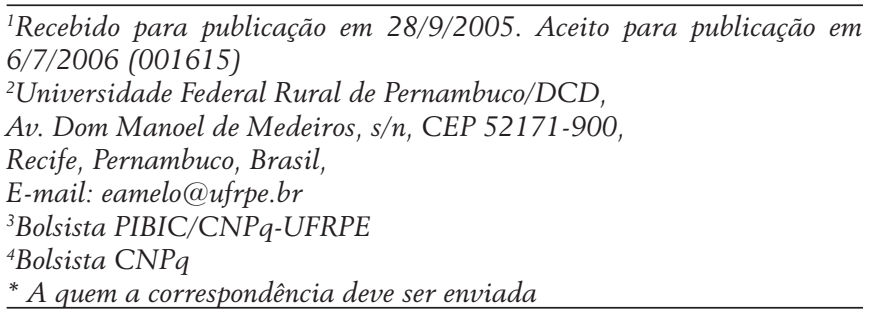

generativas. O efeito protetor exercido por estes alimentos tem sido atribuído à presença de compostos antioxidantes, dentre os quais se destacam os compostos fenólicos, além dos bem conhecidos $\beta$-caroteno, vitamina $\mathrm{C}$ e vitamina $\mathrm{E}$ [24, 29]. Os compostos fenólicos, constituintes de um amplo e complexo grupo de fitoquímicos, são produtos secundários do metabolismo vegetal que apresentam em sua estrutura um anel aromático com uma ou mais hidroxilas, o que possibilita atuarem como agentes redutores, exercendo proteção ao organismo contra o "stress" oxidativo [25].

A constatação de que os vegetais possuem substâncias biologicamente ativas que trazem benefícios à saúde ou efeitos fisiológicos desejáveis tem impulsionado estudos sobre a sua propriedade antioxidante. O efeito antioxidante de vegetais foi, inicialmente, evidenciado por CHIPAULT et al. [3] que avaliaram a ação de 32 especiarias, das quais o alecrim e a sálvia foram consideradas as mais eficazes. Posteriormente, esta ação foi constatada na soja e produtos de soja [22], na canela [16], no espinafre e repolho [9], na maçã [13], no coentro [18], entre outros.

A eficácia da ação antioxidante dos componentes bioativos depende de sua estrutura química e da concentração 
destes fitoquímicos no alimento. Por sua vez, o teor destes fitoquímicos em vegetais é amplamente influenciado por fatores genéticos, condições ambientais, além do grau de maturação e variedade da planta, entre outros. Constatase, ainda, que a atividade antioxidante é influenciada pelo substrato lipídico utilizado no ensaio, o solvente e a técnica de extração empregados [5, 14]. No que concerne aos solventes orgânicos, o metanol, por conseguir extrair elevada quantidade de compostos bioativos, tem sido apontado como o mais efetivo [4].

Em função da grande diversidade química existente, particularmente, entre os compostos fenólicos, vários ensaios têm sido desenvolvidos para avaliar a capacidade antioxidante de diferentes amostras. Alguns deles determinam a habilidade dos antioxidantes para seqüestrar radicais livres gerados no meio da reação, outros avaliam a eficiência dos antioxidantes em inibir a peroxidação lipídica por meio da quantificação dos produtos da reação, como dienos conjugados e hidroperóxidos, bem como dos produtos de decomposição da peroxidação lipídica ou medindo a inibição da oxidação do lipídio do sistema pelo antioxidante a ser testado. Não obstante a diversidade de métodos para avaliar a atividade antioxidante, não existe um procedimento metodológico universal [6]. Este fato impõe a necessidade de avaliar a capacidade antioxidante por diferentes ensaios, com mecanismo de ação diferente.

Dentre os diferentes métodos existentes destacam-se o ensaio do DPPH (1,1-difenil-2-picrilhidrazil) e o da oxidação acoplada do $\beta$-caroteno/ácido linoléico. No primeiro, o antioxidante reage com o radical DPPH, convertendo-o em sua forma reduzida (1,1-difenil-2-picrilhidrazina). Nesta reação, a solução metanólica de DPPH, inicialmente de coloração violeta, torna-se amarelada e o grau deste descoramento indica a habilidade do antioxidante em seqüestrar o radical livre. No ensaio da oxidação acoplada do $\beta$-caroteno/ácido linoléico, o sistema modelo ao ser submetido às condições de oxidação gera radical livre a partir da oxidação do ácido linoléico que irá abstrair o hidrogênio da molécula insaturada do $\beta$-caroteno. Como resultado da oxidação desta molécula, o sistema perde a sua coloração alaranjada característica que é monitorada espectrofotometricamente de modo a quantificar o grau de inibição da oxidação pelo antioxidante a ser testado [1, 20].

Desta forma, este trabalho teve como objetivo avaliar a propriedade antioxidante de hortaliças comercializadas na Cidade do Recife por meio da capacidade de seqüestrar o radical estável DPPH e da inibição da oxidação lipídica no sistema modelo $\beta$-caroteno/ácido linoléico, dois métodos bastante utilizados.

\section{2 - MATERIAL E MÉTODOS}

As hortaliças foram adquiridas mensalmente no comércio local, respeitando o calendário de comercialização da CEAGEPE no qual é indicado o período de alta oferta dos produtos no mercado, e analisadas, quanto ao teor de fenólicos totais e a capacidade antioxidante, no Laboratório de Análises Físico-químicas de Alimentos do Departamento de Ciências Domésticas da UFRPE.

\section{a) Obtenção do extrato}

Os vegetais foram descascados, conforme a necessidade, e triturados em multiprocessador. Uma alíquota da porção comestível ( 15 a 200 g - Tabela 1) foi mantida, por 20 min, sob agitação permanente, em $30 \mathrm{~mL}$ de metanol à temperatura ambiente $\left(28 \pm 2{ }^{\circ} \mathrm{C}\right) \mathrm{e}$, em seguida, filtrada. O resíduo foi novamente submetido ao processo de extração, acima explicitado, por mais dois períodos de $20 \mathrm{~min}$, totalizando um tempo de extração de $60 \mathrm{~min}$. Os filtrados resultantes foram combinados, concentrados sob pressão reduzida a $40{ }^{\circ} \mathrm{C}$ e o volume final aferido para $50 \mathrm{~mL}$.

TABELA 1 - Quantidade da porção comestível utilizada para obtenção do extrato metanólico das hortaliças.

\begin{tabular}{lclc}
\hline \multicolumn{1}{c}{ Vegetais } & Quantidade $^{(\mathbf{g})^{*}}$ & Vegetais & Quantidade $\mathbf{( g )}^{\boldsymbol{*}}$ \\
\hline Alface crespa & 200 & Couve-flor & 50 \\
Alface lisa & 200 & Couve folha & 15 \\
Batata inglesa & 100 & Espinafre & 50 \\
Cebola branca & 50 & Pepino & 200 \\
Cebola roxa & 50 & Repolho & 100 \\
Cenoura & 200 & Tomate & 100 \\
Chuchu & 200 & Vagem & 100 \\
\hline
\end{tabular}

* Quantidade definida em função do teor de fenólicos totais dos vegetais.

\section{b) Fenólicos totais}

O extrato metanólico obtido foi utilizado para a determinação dos teores de fenólicos totais, por método espectrofotométrico, utilizando o reagente Folin-Ciocalteau (Merck), segundo metodologia descrita por WETTASINGHE \& SHAHIDI [30] e curva padrão de catequina. Os resultados foram expressos em $\mu \mathrm{g}$ de fenólicos totais em equivalente de catequina por $\mathrm{mL}$ do extrato.

\section{c) Atividade antioxidante}

A atividade antioxidante do extrato foi determinada, isoladamente, em dois ensaios, a saber:

1) capacidade de seqüestrar o radical DPPH, segundo método descrito por BRAND-WILLIAMS, COUVELIER \& BERSET [2], modificado por MILIAUSKAS, VENSKUTONIS \& VAN BEEK [19]. Alíquotas (0,1 mL e 0,2 mL) dos extratos dos vegetais, com concentrações de fenólicos totais de $26 \mu \mathrm{g}$ a $220 \mu \mathrm{g}$, foram colocadas em diferentes tubos de ensaio. Em seqüência, 3,9 mL da solução de DPPH em metanol $\left(5 \times 10^{-5} \mathrm{M}\right)$ foram adicionados e, após agitação, os tubos foram deixados em repouso ao abrigo da luz. Ao final de 15, 30, 45 e $60 \mathrm{~min}$, a absorbância foi medida a $515 \mathrm{~nm}$ e a capacidade de seqüestrar o radical, expressa como percentual de inibição, calculada de acordo com a seguinte equação matemática:

$\%$ de inibição $=\frac{\text { Abs controle }- \text { Abs amostra }}{\text { Abs controle }} \times 100$ 
Onde: Abs controle = absorbância do controle (solução de DPPH sem antioxidante)

Abs amostra $=$ absorbância da amostra a ser testada

2 ) oxidação acoplada do $\beta$-caroteno e ácido linoléico, segundo a metodologia descrita por MARCO [15], modificada por HAMMERSCHMIDT \& PRATT [7], como segue: a solução de $\beta$-caroteno ( $1 \mathrm{~mL}$ ), preparada pela dissolução de $1 \mathrm{mg}$ de $\beta$-caroteno em $10 \mathrm{~mL}$ de clorofórmio, foi colocada em um balão de fundo redondo, contendo $20 \mathrm{mg}$ de ácido linoléico e $200 \mathrm{mg}$ do emulsificante Tween 20. Após a remoção do clorofórmio, em evaporador rotatório a $50{ }^{\circ} \mathrm{C}, 50 \mathrm{~mL}$ de água destilada foram adicionados sob agitação vigorosa. Alíquotas (5 mL) desta emulsão foram transferidas para uma série de tubos de ensaios contendo $0,2 \mathrm{~mL}$ do extrato dos vegetais, com concentração de fenólicos totais de 51 a $220 \mu \mathrm{g}$. Em seguida, os tubos foram colocados em banho-maria a $50{ }^{\circ} \mathrm{C}$, durante $105 \mathrm{~min}$, e a absorbância foi registrada a $470 \mathrm{~nm}$. A atividade antioxidante foi expressa como percentual de inibição da oxidação, calculada em relação a 100\% da oxidação do controle (sem antioxidante).

Como termo de comparação foram utilizadas a capacidade de seqüestrar o radical DPPH e a atividade antioxidante do BHT (butil hidroxitolueno), determinadas nas mesmas condições dos dois ensaios acima descritos.

\section{d) Tratamento estatístico dos dados}

Todas as determinações foram efetuadas em triplicata, os dados obtidos foram submetidos à análise de variância e Teste de Tukey, ao nível de significância de 5\%, utilizando o programa estatístico "STATISTICA for Windows". O coeficiente de correlação para determinar a relação entre as variáveis, teor de fenólicos totais e atividade antioxidante dos extratos das hortaliças, foi calculado e a análise de regressão efetuada, usando o mesmo programa estatístico acima citado.

\section{3 - RESULTADOS E DISCUSSÃo}

A capacidade de seqüestrar o radical DPPH, expressa em percentual de inibição, exibida pelos extratos metanólicos dos vegetais em estudo, encontra-se na Tabela 2. Com base nestes dados, evidencia-se que o(s) composto(s) ativo(s) dos extratos atua(m) como doador de hidrogênio ao radical, entretanto esta ação é diferenciada entre os vegetais. O extrato metanólico do tomate, couve-flor, couve folha, batata e espinafre foram, nesta ordem, os mais eficazes em seqüestrar o radical livre, cujo percentual de inibição, aos 15 min da reação, foi superior a $70 \%$. Evidencia-se que a ação exibida por estes vegetais foi estatisticamente semelhante ao antioxidante sintético BHT. Com exceção do extrato metanólico da cebola roxa e da alface crespa, com ação antioxidante moderada por ter atingido 60-70\% de inibição após os 15 min da reação, as demais hortaliças, com inibição inferior a $60 \%$, exibiram uma fraca capacidade em seqüestrar o radical DPPH. Dentre as hortaliças com menor ação antioxidante destacaram-se o chuchu, pepino e a cenoura com o menor percentual de inibição.
TABELA 2 - Capacidade de seqüestrar o radical DPPH (\% de inibição) de extratos metanólicos de hortaliças, contendo 0,03 a $0,4 \mathrm{~g}$ de amostra/0,1 mL.

\begin{tabular}{|c|c|c|c|c|c|}
\hline \multirow[t]{2}{*}{ Vegetal } & \multirow{2}{*}{$\begin{array}{c}\text { Fenólicos } \\
(\mu \mathrm{g} / 0,1 \mathrm{~mL})\end{array}$} & \multicolumn{4}{|c|}{ \% Inibição } \\
\hline & & $15 \mathrm{~min}$ & $30 \mathrm{~min}$ & $45 \mathrm{~min}$ & $60 \mathrm{~min}$ \\
\hline Alface crespa & 90,41 & $50,51^{\text {bcde }}$ & $60,16^{\text {bcd }}$ & $66,45^{\text {abcd }}$ & $69,57^{\text {abcde }}$ \\
\hline Alface lisa & 55,41 & $36,73^{e}$ & $45,62^{\mathrm{d}}$ & $53,19^{\text {cd }}$ & $60,85^{\text {bcde }}$ \\
\hline Batata & 75,01 & $79,48^{a b}$ & $82,29^{a b c}$ & $85,09^{a b}$ & $85,68^{a b c}$ \\
\hline Cebola branca & 85,23 & $39,32^{\mathrm{e}}$ & $45,50^{d}$ & $49,71^{\text {cd }}$ & $52,21^{\text {de }}$ \\
\hline Cebola roxa & 96,31 & $52,99^{\text {bcde }}$ & $62,82^{\mathrm{abcd}}$ & $70,70^{\text {abcd }}$ & $74,73^{\text {abcde }}$ \\
\hline Cenoura & 43,78 & $29,15^{\text {ef }}$ & $38,03^{d e}$ & $42,64^{\mathrm{de}}$ & $45,15^{\mathrm{e}}$ \\
\hline Couve-flor & 81,68 & $87,45^{a}$ & $87,35^{\mathrm{ab}}$ & $87,52^{\mathrm{a}}$ & $87,52^{\mathrm{abc}}$ \\
\hline Couve folha & 74,74 & $85,42^{\mathrm{a}}$ & $90,49^{\mathrm{ab}}$ & $91,63^{a}$ & $91,63^{a}$ \\
\hline Chuchu & 25,77 & $3,07^{f}$ & $4,99^{f}$ & $6,71^{f}$ & $9,80^{f}$ \\
\hline Espinafre & 112,18 & $78,86^{\mathrm{abc}}$ & $79,54^{\mathrm{abc}}$ & $79,74^{\mathrm{abc}}$ & $81,41^{a b c}$ \\
\hline Pepino & 43,04 & $5,48^{f}$ & $9,45^{\text {ef }}$ & $12,67^{\text {ef }}$ & $15,27^{f}$ \\
\hline Repolho verde & 61,27 & $45,33^{d e}$ & $51,54^{\mathrm{cd}}$ & $55,37^{\mathrm{bcd}}$ & $57,96^{\text {cde }}$ \\
\hline Tomate & 60,88 & $91,87^{\mathrm{a}}$ & $92,94^{a}$ & $92,92^{\mathrm{a}}$ & $93,53^{a}$ \\
\hline Vagem & 45,64 & $48,48^{\text {cde }}$ & $51,44^{\text {cd }}$ & $54,96^{\mathrm{bcd}}$ & $57,77^{\text {cde }}$ \\
\hline $\mathrm{BHT}$ & * & $70,83^{\mathrm{abcd}}$ & $87,83^{\text {ab }}$ & $89,34^{\mathrm{a}}$ & $90,60^{\mathrm{ab}}$ \\
\hline
\end{tabular}
não diferem estatisticamente pelo teste de Tukey ao nível de $5 \%$ de probabilidade.

A capacidade de vários vegetais de seqüestrar radical livre foi avaliada por OU et al. [21], pelo método ORAC. Estes autores evidenciaram que a maior ação antioxidante foi exibida pelo extrato metanólico do espinafre seguido pelo da cebola roxa, couve-flor, cebola branca, tomate, repolho verde e cenoura. MARTINEZ-VALVERDE et al. [17], no entanto, relatam que o extrato etanólico do tomate exibiu uma baixa eficiência em seqüestrar o radical DPPH.

A eficácia dos extratos em seqüestrar o radical DPPH, também, foi avaliada utilizando maior volume do extrato e, conseqüentemente, maior concentração de fenólicos totais (Tabela 3).

TABELA 3 - Capacidade de seqüestrar o radical DPPH (\% de inibição) de extratos metanólicos de hortaliças, contendo 0,06 a $0,8 \mathrm{~g}$ de amostra/0,2 $\mathrm{mL}$.

\begin{tabular}{lccccc}
\hline \multicolumn{1}{c}{ Vegetal } & Fenólicos & \multicolumn{4}{c}{ \% de Inibição } \\
\cline { 3 - 6 }$(\mu \mathbf{g} / \mathbf{0 , 2} \mathbf{~ m L})$ & $\mathbf{1 5} \mathbf{~ m i n}$ & $\mathbf{3 0 ~} \mathbf{~ m i n}$ & $\mathbf{4 5} \mathbf{~ m i n}$ & $\mathbf{6 0} \mathbf{~ m i n}$ \\
\hline Alface crespa & 180,75 & $70,63^{\mathrm{abc}}$ & $75,23^{\mathrm{ab}}$ & $75,25^{\mathrm{a}}$ & $75,25^{\mathrm{a}}$ \\
Alface lisa & 110,81 & $60,00^{\mathrm{bc}}$ & $69,29^{\mathrm{b}}$ & $72,38^{\mathrm{a}}$ & 73,37 \\
Batata & 150,01 & $87,56^{\mathrm{ab}}$ & $87,08^{\mathrm{ab}}$ & $88,23^{\mathrm{a}}$ & $87,98^{\mathrm{a}}$ \\
Cebola branca & 170,45 & $66,21^{\mathrm{abc}}$ & $73,26^{\mathrm{ab}}$ & $77,83^{\mathrm{a}}$ & $82,16^{\mathrm{a}}$ \\
Cebola roxa & 192,62 & $54,83^{\mathrm{cd}}$ & $71,63^{\mathrm{ab}}$ & $77,48^{\mathrm{a}}$ & $81,74^{\mathrm{a}}$ \\
Cenoura & 87,55 & $27,62^{\mathrm{de}}$ & $36,23^{\mathrm{c}}$ & $39,86^{\mathrm{b}}$ & $47,40^{\mathrm{b}}$ \\
Couve-flor & 163,42 & $86,49^{\mathrm{ab}}$ & $87,03^{\mathrm{ab}}$ & $87,25^{\mathrm{a}}$ & $87,35^{\mathrm{a}}$ \\
Couve folha & 149,47 & $91,85^{\mathrm{a}}$ & $91,99^{\mathrm{a}}$ & $92,02^{\mathrm{a}}$ & $92,31^{\mathrm{a}}$ \\
Chuchu & 51,53 & $6,31^{\mathrm{e}}$ & $13,20^{\mathrm{d}}$ & $16,61^{\mathrm{c}}$ & $19,29^{\mathrm{c}}$ \\
Espinafre & 220,56 & $71,98^{\mathrm{abc}}$ & $72,15^{\mathrm{ab}}$ & $72,95^{\mathrm{a}}$ & $72,87^{\mathrm{a}}$ \\
Pepino & 63,93 & $12,68^{\mathrm{e}}$ & $18,40^{\mathrm{cd}}$ & $22,93^{\mathrm{bc}}$ & $28,75^{\mathrm{bc}}$ \\
Repolho verde & 118,43 & $75,04^{\mathrm{abc}}$ & $83,16^{\mathrm{ab}}$ & $85,31^{\mathrm{a}}$ & $88,84^{\mathrm{a}}$ \\
Tomate & 121,76 & $87,95^{\mathrm{ab}}$ & $88,48^{\mathrm{ab}}$ & $89,09^{\mathrm{a}}$ & $89,45^{\mathrm{a}}$ \\
Vagem & 91,29 & $67,56^{\mathrm{abc}}$ & $73,71^{\mathrm{ab}}$ & $75,08^{\mathrm{a}}$ & $76,31^{\mathrm{a}}$ \\
BHT & $*$ & $87,10^{\mathrm{ab}}$ & $91,11^{\mathrm{ab}}$ & $91,18^{\mathrm{a}}$ & $91,71^{\mathrm{a}}$ \\
\hline
\end{tabular}

Média de três determinações; * $500 \mu \mathrm{g} / 0,2 \mathrm{~mL}$; Médias seguidas de mesma letra na coluna não diferem estatisticamente pelo teste de Tukey ao nível de $5 \%$ de probabilidade. 
A análise dos dados permitiu evidenciar que, nos primeiros quinze minutos da reação, a maior ação, em ordem decrescente, foi exibida pelo extrato metanólico da couve folha, tomate, batata, couve-flor, repolho verde, espinafre e alface crespa, todos com percentual de inibição superior a $70 \%$. A capacidade de seqüestrar o radical DPPH destas hortaliças foi estatisticamente semelhante ao BHT. Capacidade moderada de seqüestrar o radical (60-70\%) foi apresentada pelo extrato metanólico da vagem, cebola branca e alface lisa, enquanto que a mais fraca capacidade de seqüestrar o radical DPPH ( $<60 \%$ ) foi exibida pela cebola roxa, cenoura, pepino e chuchu. Aos 30, 45 e 60 min da reação, a couve folha manteve sua superioridade sem, contudo, diferir estatisticamente do BHT e das demais hortaliças, exceto da cenoura, do chuchu e do pepino que continuaram a exibir a menor ação.

Na Tabela 3, evidencia-se que o extrato metanólico da couve folha, apesar de apresentar teor de fenólicos totais inferior ao do extrato do espinafre, couve-flor, cebola branca, cebola roxa e alface crespa, exibiu a maior capacidade de seqüestrar o radical DPPH. Observa-se, ainda, que a maioria dos extratos exibiu maior capacidade de seqüestrar o radical DPPH ao serem utilizadas alíquotas com maior teor de compostos fenólicos, no entanto, o extrato metanólico da couve-flor, espinafre e tomate apresentaram leve redução desta ação (Tabelas 2 e 3). O teor de fenólicos totais, nos dois ensaios ( 0,1 e 0,2 mL dos extratos), bem como o percentual de inibição dos extratos das hortaliças apresentou um baixo coeficiente de correlação $(\mathrm{R}=0,60 \mathrm{e}$ 0,52 respectivamente, $\mathrm{p}<0,05$ ). $\mathrm{Na}$ análise de regressão $(\mathrm{p}<0,05)$ evidencia-se que não houve um aumento linear da capacidade de seqüestrar o radical DPPH em função do teor de fenólicos totais (Figura 1).

Vários autores têm demonstrado de forma conclusiva que existe uma forte relação positiva entre o teor de fenólicos totais e a atividade antioxidante de frutas e hortaliças [ 1,11 , 27,28 ], enquanto que outros autores não têm evidenciado esta correlação [9, 10]. A composição química e a estrutura química do componente ativo do extrato são fatores importantes que influenciam a eficácia do antioxidante natural. A posição e o número de hidroxilas presentes na molécula dos polifenóis é um fator relevante para esta atividade. Acreditase que a orto-dihidroxilação contribui marcadamente para a atividade antioxidante do composto [26]. Assim, a atividade antioxidante de um extrato não pode ser explicada apenas com base em seu teor de fenólicos totais, a caracterização da estrutura do composto ativo, também, é necessária [8].

A ação antioxidante do extrato metanólico das hortaliças também foi avaliado no sistema modelo $\beta$-caroteno/ácido linoléico, cujos resultados variaram de $10,91 \%$ a $81,86 \%$ de inibição (Figura 2). Evidencia-se, portanto, que a presença do extrato das hortaliças, contendo fitoquímicos antioxidantes, reduziu, em graus diferentes, o descoramento do $\beta$-caroteno. Em função do percentual de inibição exibido, o espinafre e a couve folha foram classificados como os vegetais com elevada ação antioxidante (> 70\%), não diferindo estatisticamente do BHT. No grupo com moderada ação
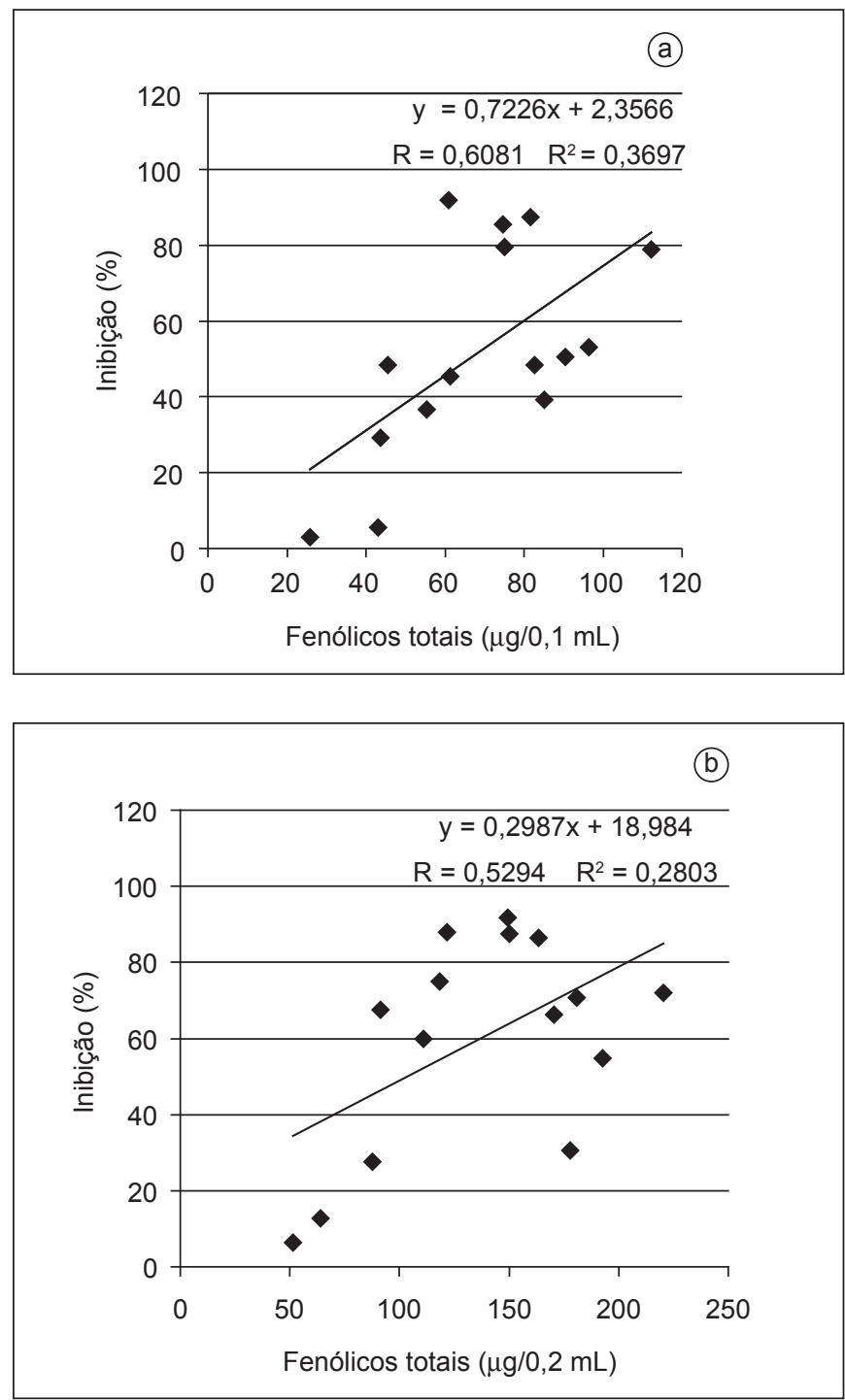

FIGURA 1 - Relação entre o teor de fenólicos totais e a capacidade de seqüestrar o radical DPPH (percentual de inibição) dos extratos metanólicos das hortaliças comercializadas em Recife.

antioxidante (60-70\%), estão a alface lisa, a cebola branca e a couve-flor. Os demais vegetais estudados, por exibirem percentual de inibição da oxidação inferior a $60 \%$, foram considerados com fraca ação antioxidante, dentre os quais se destacaram o chuchu, cenoura, pepino, tomate e vagem com os menores percentuais.

Utilizando a oxidação acoplada do $\beta$-caroteno e ácido linoléico para avaliar a capacidade antioxidante de vegetais, KAUR \& KAPOOR [11] consideraram elevada a ação antioxidante do extrato etanólico do tomate, uma vez que atingiu um percentual de inibição da oxidação superior a 70\%. Nesse mesmo ensaio, a ação antioxidante do extrato etanólico do repolho, variedade capitata, cenoura e batata foi considerada moderada (60-70\% de inibição), enquanto que a do extrato de cebola, pepino, couve-flor foi baixa (<60\%). Evidencia-se, portanto, que a intensidade da atividade antioxidante das 


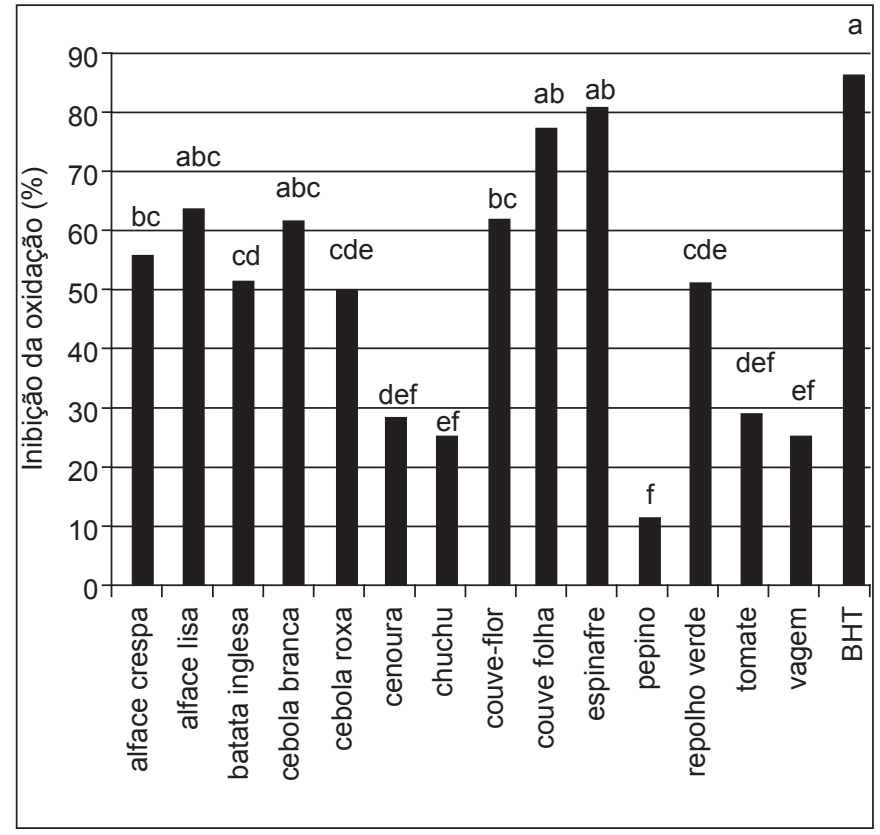

FIGURA 2 - Atividade antioxidante de extrato metanólico de hortaliças contendo 51,53 a 220,56 $\mu \mathrm{g}$ de fenólicos totais/0,2 mL, determinada pela oxidação acoplada do $\beta$-caroteno/ácido linoléico

hortaliças deste estudo é diferente da relatada por outros autores. Vários fatores relacionados ao cultivo do vegetal, a exemplo das condições climáticas e edáficas, além das características genéticas da planta, influenciam o perfil de compostos fenólicos das hortaliças e, conseqüentemente, a sua ação antioxidante.

Na relação entre o teor de fenólicos totais e a atividade antioxidante, apresentada na Figura 3, evidencia-se uma positiva e significante correlação entre estas variáveis ( $p<0,05)$ $\left(\mathrm{R}=0,7805 ; \mathrm{R}^{2}=0,6092\right)$. Comportamento semelhante foi evidenciado por KAUR \& KAPOOR [11] usando o reagente Folin Ciocalteau para determinação de teor de fenólicos e o sistema modelo $\beta$-caroteno/ácido linoléico para avaliar a atividade antioxidante de extrato etanólico de vegetais.

A ação dos extratos das hortaliças testadas nos dois ensaios (DPPH e $\beta$-caroteno/ácido linoléico) foi diferenciada. Enquanto no ensaio do DPPH, o tomate e a couve folha exibiram a maior atividade de seqüestrar o radical, o espinafre e a couve folha exibiram a maior atividade antioxidante no ensaio $\beta$-caroteno/ácido linoléico. Neste último, o extrato metanólico do tomate apresentou um dos menores percentuais de inibição da oxidação (28,58\%). Estas discrepâncias podem ser inerentes às características e ao mecanismo de ação do(s) composto(s) bioativo(s) e a metodologia utilizada para avaliar sua propriedade antioxidante.

Segundo KOLEVA et al. [12], a oxidação lipídica é um complexo processo em cadeia, no qual estão envolvidos vários tipos de radicais livres de diferentes reatividades, e a ação antioxidante de um composto bioativo depende do substrato lipídico, da sua solubilidade e do seu me-

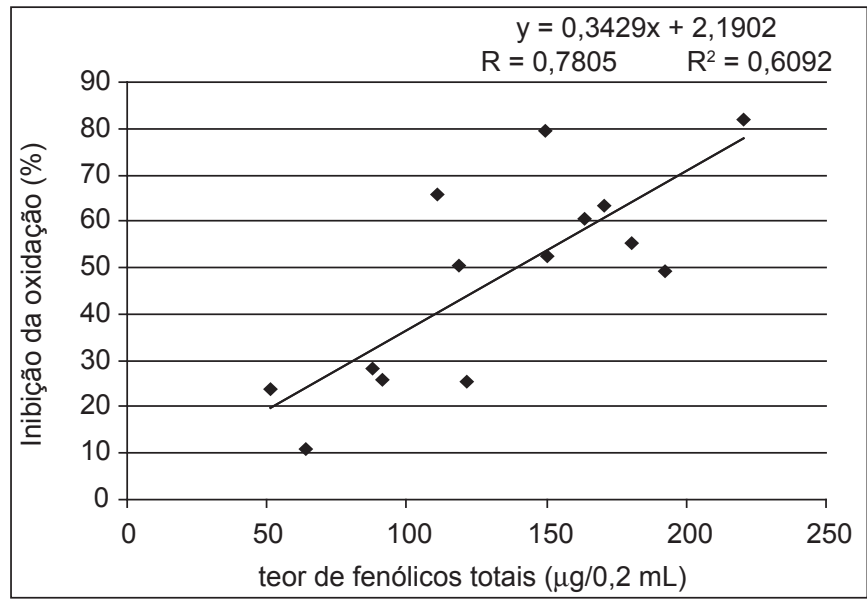

FIGURA 3 - Relação entre o teor de fenólicos totais e a ação antioxidante dos extratos metanólicos das hortaliças comercializadas em Recife.

canismo de ação. Assim, em ensaios que contém lipídios como substrato oxidável, a exemplo da oxidação acoplada $\beta$-caroteno/ácido linoléico, o papel protetor do antioxidante depende de sua solubilidade que determina sua distribuição na fase do sistema, incluindo localização e orientação. Além disso, a complexa composição dos extratos de vegetais pode provocar interações sinérgicas ou antagônicas entre os compostos presentes, podendo, também, afetar sua partição nas fases do meio e, conseqüentemente, sua ação antioxidante. Ainda, segundo KOLEVA et al. [12], o exato mecanismo do antioxidante no sistema $\beta$-caroteno/ácido linoléico é difícil de ser explicado, especialmente ao testar a ação de matrizes complexas, como os extratos de vegetais. Por outro lado, o ensaio do DPPH avalia a capacidade do antioxidante de seqüestrar o radical, portanto não está associado à degradação lipídica oxidativa nem à hidro/lipossolubilidade do composto antioxidante, pois o sistema não contém substrato oxidável, depende principalmente da sua estrutura química. Neste caso, avalia-se a habilidade do antioxidante em doar hidrogênio.

\section{4 - CONCLUSÃO}

Todas as hortaliças estudadas apresentaram propriedade antioxidante, entretanto a intensidade desta ação foi diferenciada entre elas. O extrato da couve folha possui composto(s) bioativo(s) que apresenta(m) uma potente ação antioxidante, pois exibiu a maior atividade antioxidante e a mais elevada capacidade de seqüestrar o radical DPPH. No entanto, frente à ação antioxidante exibida, todas as hortaliças podem ser vistas como fontes dietéticas de antioxidantes naturais que podem trazer benefícios à saúde, cujo consumo deve ser estimulado.

\section{5 - REFERÊNCIAS BIBLIOGRÁFICAS}

[1] ABIDILlE, M. D. H.; SINGH, R. P.; JAYAPRAKASHA, G. K.; JENA, B. S. Antioxidant activity of the extracts 
from Dillenia indica fruits. Food Chem., v. 90, n.4, p. 891-896, 2005.

[2] BRAND-WILliAMS, W.; CUVELIER, M. E.; BERSET, C. Use of free radical method to evaluate antioxidant activity. Lebensm. Wiss. Techonol., v. 28, n. 1, p. 25-30, 1995.

[3] ChipAUlT, J. R.; MIZUN, G. K.; HAWKINS, J. M.; LUNDBERG, W. O. The antioxidant properties of natural spices. Food Res., v. 17, p. 46-55, 1952.

[4] ECONOMOU, K. D.; OREOPOULOU, V.; THOMOPOULOS, C. D. Antioxidant activity of some plant extracts of the family Labiatae. J. Am. Oil Chem. Soc., v. 68, n. 2, p.109-113, 1991.

[5] FRANKEL, E. N. In search of better methods to evaluate natural antioxidants and oxidative stability in food lipids. Food Sci. Technol., v. 4, p. 220-225, 1993.

[6] FRANKEL, E. N.; MEYER, A. S. The problems of using one-dimensional methods to evaluate multifunctional food and biological antioxidants. J. Scie. Food Agric., v. 80, n. 13, p. 1925-1941, 2000.

[7] HAMMERSCHMIDT, P. A.; PRATT, D. E. Phenolic antioxidants of dried soybeans. J. Food Sci., v. 43, p. 556-559, 1978.

[8] Heinonen, M.; Lehtonen, P. J.; HOPIA, A. Antioxidative activity of berry and fruit wines and liquor. J. Agric. Food Chem., v. 48, n. 1, p. 25-31, 1998.

[9] ISMAIL, A.; MARJAN; Z. M.; FOONG, C. W. Total antioxidant activity and phenolic content in selected vegetables. Food Chem., v. 87, n. 4, p. 581-586, 2004.

[10] KAHKONEN, M. P.; HOPIA, A. I.; VUORELA, H. J.; RAUHA J. P.; PIHLAJA, K.; KUJALA, T. S.; HEINONEN, M. Antioxidant activity of plant extracts containing phenolic compounds. J. Agric. Food Chem., v. 47, n. 10, p. 3954-3962, 1999.

[11] KAUR, C.; KAPOOR, H. C. Anti-oxidant activity and total phenolic content of some Asian vegetables. Int. J. Food Sci. Technol., v. 37, n. 2, p. 153-161, 2002.

[12] KOLEVA, I. I.; VAN BEEK, T. A.; LINSSEN, J. P. H.; GROOT A.; EVSTATIEVA, L. N. Screening of plant extracts for antioxidant activity: a comparative study on three testing methods. Phytochem. Anal., v. 13, p. 8-17, 2002.

[13] LEJA, M.; MARECZEK, A.; BEN, J. Antioxidant properties of two apple cultivars during long-term storage. Food Chem., v. 80, p. 303-307, 2003.

[14] MADSEN, H. L.; BERTELSEN, G. Spices as antioxidants. Trends Food Sci. Technol., v. 6, p. 271-277, 1995.

[15] MARCO, G. J. A rapid method for evaluation of antioxidants. J. Am. Oil Chem. Soc., v. 45, p. 594-598, 1968.

[ 16] MANCINI FILHO, J.; VAN-KOIIJ, A.; MANCINI, D. A. P.; COZZOLINO, F. F.; TORRES, R.P. Antioxidant activity of cinnamon (Cinnamomun zeylanicum, Breyne) extracts. Boll. Chim. Farmaceutico, v. 137, n. 11, p. 443-447, 1998.

[17] MARTINEZ-VALVERDE, I.; PERIAGO, M. J.; PROVAN, G; CHESSON, A. Phenolic compounds, lycopene and antioxidant activity in commercial varieties of tomato (Lycopersicum esculentum). J. Sci. Food Agric., v. 82, p. 323-330, 2002.

[18] MELO, E. A; MANCINI FILHO, J.; GUERRA, N. B. Characterization of antioxidant compounds in aqueous coriander extract (Coriandrum sativum L.). Lebensm. Wiss. Techonol., v. 38, n. 1, p. 15-19, 2005.

[19] MILIAUSKAS, G.; VENSKUTONIS, P. R.; VAN BEEK, T. A. Screening of radical scavenging activity of some medicinal and aromatic plant extracts. Food Chem., v. 85, p. 231-237, 2004.

[20] MOLYNEUX, P. The use of the stable free radical diphenylpicryl-hydrazil (DPPH) for estimating antioxidant activity. Songklanakarin J. Sci. Technol., v. 26, n. 2, p. 211-219, 2003.

[21] OU, B.; HUANG, D.; HAMPSCH-WOODILL, M.; FLANAGAN, J. A.; DEEMER, E. K. Analysis of antioxidant activities of common vegetables employing oxygen radical absorbance capacity (ORAC) and ferric reducing antioxidant power (FRAP) assays: a comparative study. J. Agric. Food Chem., v. 50, p. 3122-3128, 2002.

[22] PRATT, D. E.; BIRAC, P. M. Source of antioxidant activity of soybeans and soy products. J. Food Sci., v. 44, p. 1720-1722, 1979.

[23] RAMARARHNAM, N.; OSAWA, T.; OCHI, H.; KAWAKISHI, S. The contribution of plant food antioxidants to human health. Trends Food Sci. Technol., v. 6, n. 3, p. 75-82, 1995.

[24] RICE-EVAnS, C. A.; MilleR, N. J.; PAGANGA, G. Structure antioxidant activity relationship of flavonoids and phenolic acid. Free Radical Biol. Med., v. 20, n. 7, p. 933-956, 1996.

[25] SCALBERT, A.; WILliAMSON, G. Dietary intake and bioavailability of polyphenols. J. Nutr., v. 130, p. 2073-2085, 2000.

[26] SHAHIDI, F.; JANITHA, P. K.; WANASUNDARA, P. D. Phenolic antioxidants. CRC-Crit. Rev. Food Sci. Nutr., v. 32, n. 1, p. 67-103, 1992.

[27] VELIOGLU, Y. S.; MAZZA, G.; GAO, L.; OOMAH, B. D. Antioxidant activity and total phenolics in selected fruits, vegetables and grain products. J. Agric. Food Chem., v. 46, p. 4113-4117, 1998.

[28] VISON, J. A.; HAO, Y.; SU, X.; ZUBIK, L. Phenol antioxidant quantity and quality in foods: vegetables. J. Agric. Food Chem., v. 46, p. 3630-3634, 1998.

[29] WANG, H.; CAO, G.; PRIOR, R. L. Total antioxidant capacity of fruits. J. Agric. Food Chem., v. 44, n. 3, p. 701-705, 1996.

[30] WETTASINGHE, M.; SHAHIDI, F. Evening primrose meal: a source of natural antioxidants and scavenger of hydrogen peroxide and oxygen-derived free radicals. J. Agric. Food Chem., v. 47, p. 1801-1812, 1999.

\section{6 - AGRADECIMENTOS}

À FACEPE (Edital PP) e ao CNPq (Edital Universal) pelos auxílios financeiros. Ao CNPq pela bolsa de apoio técnico de A. C. S. CAETANO. 